\title{
Morbidade Materna e Morbimortalidade Perinatal Associada à Infecção Ascendente na Rotura Prematura das Membranas
}

\author{
Maternal Morbidity and Perinatal Morbidity and Mortality Associated with Ascendant \\ Infection in Premature Rupture of Membranes
}

\begin{abstract}
José Elias Soares da Rocha, Ana Claire Pimenteira Tomaz, Dinalva Bezerra da Rocha,
Antônio Fernando Bezerra, Ana Luzia de Campos Lopes, Ana Maria Omena Breda, Silvia Danielle Alves Souza
\end{abstract}

\section{RESUMO}

Objetivo: avaliar as repercussões da infecção ascendente sobre a mãe, o feto e o recémnascido (RN) nos casos de rotura prematura das membranas (RPM).

Métodos: estudo prospectivo, avaliando 50 gestantes portadoras de RPM e seus RN. A corioamnionite clínica foi rastreada por meio de critérios clínicos (curva térmica, dor abdominal à palpação e/ou amolecimento uterino, odor e características da secreção vaginal) $e$ subsidiários (leucograma e proteina $C$ reativa). Por sua vez, a corioamnionite histológica foi avaliada com estudo macroscópico e microscópico da placenta, membranas e cordão umbilical. No estudo microscópico, utilizou-se a microscopia óptica com coloração pela hematoxilinaeosina. Os $R N$ foram avaliados pela mensuração do peso e indice de Apgar no $1^{\circ}$ e $5^{\circ}$ minuto. O leucograma e a cultura do material colhido do ouvido e aspirado gástrico complementaram o estudo. Para análise estatística foram utilizados os testes exato de Fisher e t de Student, com nivel de significância de $5 \%(p<0,05)$.

Resultados: a taxa de corioamnionite clinica foi de 29,4\% (15/50), ao passo que a de corioamnionite histológica foi de 40\% (20/50). Todos os casos de corioamnionite clínica apresentaram periodo de latência (PL) superior a 24 horas. Os RN apresentaram sinais de infecção em 31,4\% (16/51), todos com PL maior que 24 horas. Os principais microrganismos isolados do conduto auditivo e aspirado gástrico dos RN foram: Klebsiella pneumoniae, Staphylococcus aureus, cocos Gram positivos e Streptococcus agalactiae - Grupo B de Lancefield (SGB). Os RN infectados apresentaram menor escore de Apgar no $1^{\circ}$ e $5^{\circ}$ minuto, peso ao nascer inferior e maior morbidade e mortalidade perinatal quando comparados com os RN não infectados.

Conclusões: baseados na análise dos resultados obtidos no presente estudo, foi possível concluir que o periodo de latência prolongado aumenta a chance de infecção ascendente, que, por sua vez, proporciona maior probabilidade de parto prematuro, aumentando portanto a morbidade materna (corioamnionite clínica), bem como a morbidade e mortalidade perinatal.

PALAVRAS-CHAVE: Rotura prematura das membranas. Infecção ascendente. Corioamnionite.

\section{Introdução}

Apesar dos avanços científicos e tecnológicos na vigência do terceiro milênio, a rotura prema-

Departamento de Tocoginecologia e Pediatria da Universidade Federal de Alagoas (UFAL)

Correspondência:

José Elias Soares da Rocha

Av. Prof. Vital Barbosa, $\mathrm{n}^{\circ} 1136$, Apto 402 - Ponta Verde 57035-570 - Maceió - AL

Apoio Financeiro: PIBIC-CNPq/UFAL. tura das membranas (RPM) continua sendo um desafio para o obstetra e certamente o será para aqueles que irão militar na especialidade no século XXI.

As principais repercussões maternas incluem aumento na taxa de cesárea, corioamnionite clínica e infecção pós-parto, ao passo que o risco perinatal inclui, entre outros, prematuridade, infecção, sepse neonatal e óbito fetal e neonatal ${ }^{1-5}$.

Com a finalidade de obter maturidade pulmonar fetal a conduta expectante, com ou sem a 
utilização de corticosteróides, tem sido freqüentemente adotada, obviamente diante dos casos bem selecionados e na ausência de contra-indicações para tal medida. Por sua vez, adotando-se a conduta expectante, a cavidade amniótica fica exposta aos microrganismos que sabidamente habitam a vagina e o canal endocervical. Surge então, a possibilidade da contaminação daquela cavidade através das membranas por via ascendente, fato demonstrado pelo achado de microrganismos no liquido amniótico (LA) semelhantes àqueles habitualmente encontrados no trato genital inferior ${ }^{6}$.

A atividade antimicrobiana do LA é limitada e depende de fatores como concentração do complexo zinco-protéico, lisozima, etc., presentes no próprio fluído, além da idade gestacional e presença de mecônio. Por sua vez, a sensibilidade e a resistência dos micro-organismos ao LA devem ser levadas em consideração no tocante ao desencadeamento de infecção da cavidade amniótica. Estudo realizado por Duarte ${ }^{7}$ demonstrou que os micro-organismos anaeróbios apresentam elevada sensibilidade aos componentes do LA, ao passo que o Streptococcus agalactiae - grupo B de Lancefield resiste à ação dos compostos antibacterianos desse fluido, aspecto que corrobora os achados de colonização de bactérias na cavidade amniótica, mesmo diante de membranas integras.

$\mathrm{O}$ fato de afetar entre 2,7 e $17 \%$ das gestações $^{8}$, com uma média de $10 \%{ }^{9}$, a RPM se faz presente especialmente na população de grávidas atendidas nos serviços públicos do nosso país, despertando portanto, o interesse dos pesquisadores sobre o assunto.

Considerando-se uma incidência significante e o tipo de população acometida por essa intercorrência obstétrica, associado à importância das repercussões da infecção ascendente (IA) sobre o binômio materno-fetal, o objetivo do presente estudo foi avaliar as possiveis complicações maternas e perinatais nos casos de infecção ascendente decorrente de RPM.

\section{Pacientes e Métodos}

Foram estudadas prospectivamente 50 gestantes com diagnóstico de RPM atendidas na Maternidade Escola (ME) do Hospital Universitário da Universidade Federal de Alagoas (HU-UFAL), no período compreendido entre agosto de 1996 e agosto de 1998.

A concordância em participar do estudo foi verbal e aprovada pelo Conselho de Ética do HU/ UFAL, excluindo-se aquelas que não concordavam em participar.
O diagnóstico da RPM foi realizado por meio da história da paciente, com queixa de perda líquida através da vagina, e do exame clínico, com a utilização de espéculo vaginal. Foi compativel com membranas rotas a visualização de LA escoando através do orificio externo da cérvice, excluindo-se os casos duvidosos. A ecografia em tempo real foi utilizada como método complementar, tendo sido sugestivo de amniorrexe os casos de oligoidramnia grave com história clínica de perda líquida através da vagina, excluindo-se outras causas que podem provocar redução do LA.

O critério de inclusão das pacientes no estudo obedeceu a requisitos previamente estabelecidos, a saber: idade gestacional compreendida entre 28 e 40 semanas e RPM com periodo de latência de pelo menos 6 horas. Não foram incluidas portadoras de diabete melito, cardiopatias, hipertensão arterial aguda e/ou crônica, sensibilização ao $\mathrm{Rh}$, infecção urinária, outras infecções localizadas e/ou sistêmicas, além de doenças e/ou situações que sabidamente comprometem o sistema imunológico da gestante, como colagenoses, uso de corticosteróides, drogas imunossupressoras e outras.

O rastreamento da corioamnionite clínica foi realizado por critérios clínicos e subsidiários. Os critérios clínicos consistiram de exame clínico geral para afastar infecções urinária, respiratória e dos demais sistemas. Pesquisou-se, ainda, odor e características da secreção vaginal, bem como queixa de dor abdominal à palpação e/ou amolecimento uterino. A curva térmica foi realizada por meio da mensuração da temperatura axilar com intervalo de 6 horas.

Os exames subsidiários utilizados para rastrear corioamnionite clínica foram o leucograma e a proteína $\mathrm{C}$ reativa (PCR) quantitativa, realizados a cada dois dias. O leucograma foi considerado alterado quando a contagem total de leucócitos era $>15000 / \mathrm{mm}^{3}$ com desvio à esquerda ou um aumento superior a $50 \%$ do nível basal com desvio à esquerda. A dosagem quantitativa da PCR foi considerada anormal com valores $\geq 6,5 \mathrm{mg} / \mathrm{L}$ (valor de referência do laboratório).

Considerou-se quadro sugestivo de infecção intra-amniótica (corioamnionite clínica) a presença de sinais/sintomas clínicos característicos: febre materna, dor abdominal e amolecimento uterino à palpação, perda vaginal com odor fétido e/ou purulenta geralmente associada a um exame subsidiário alterado. Saliente-se que a presença de corioamnionite clínica implicava a interrupção da gestação (inicialmente pela indução do trabalho de parto com utilização de ocitocina e cesárea para os casos de insucesso com a indução) e administração de antibióticos, segundo protocolo da ME do HU-UFAL. 
O rastreamento de infecção materna pósparto, foi realizado durante o tempo em que permaneceram internadas no hospital, sendo avaliadas diariamente por meio da análise da curva térmica, tamanho, consistência e sensibilidade uterina, características dos lóquios e observação do aspecto da cicatriz da episiotomia ou da cesárea. No momento da alta hospitalar, as pacientes foram orientadas para retornar ao serviço no $10^{\circ}$ dia pós-parto para revisão e/ou caso apresentassem qualquer sinal de infecção dentro dos primeiros 45 dias.

O estudo histopatológico das membranas, placenta (placas, basal e corial) e cordão umbilical foi realizado com fragmentos obtidos por biópsia. Os tecidos foram impregnados em parafina e os blocos foram cortados em micrótomo com espessura de cerca de $7 \mu$. Em seguida foram colocados em lâminas e corados pela hematoxilina/eosina. Montou-se com bálsamo entre lâminas e laminulas. As lâminas contendo os cortes dos tecidos foram examinadas ao microscópio óptico. Foi estabelecido o grau de infiltrado inflamatório pela presença de leucócitos polimorfonucleares.

Os recém-nascidos (RN) foram avaliados imediatamente ao nascer, por meio do exame clínico para rastrear infecção, do leucograma, além da mensuração do peso, estatura e índice de Apgar no $1^{\circ}$ e $5^{\circ}$ minuto. Nos casos de óbito fetal realizou-se a necropsia.

Para analisar estatisticamente os resultados obtidos no presente estudo, utilizaram-se percentagem, média, desvio padrão, o teste $t$ de Student e o teste exato de Fisher, com nivel de significância de $5 \%(\mathrm{p}<0,05)$.

\section{Resultados}

Um total de 50 pacientes com RPM e seus RN tiveram um acompanhamento completo e constituíram a casuística do presente estudo.

A Tabela 1 mostra a distribuição das pacientes estudadas quanto a média de idade, cor, estado civil, paridade, número de abortos prévios, tipo de parto, período de latência e idade gestacional na resolução da gravidez. Saliente-se que as pacientes que cursaram com corioamnionite clínica apresentaram um intervalo entre a rotura das membranas e o início do trabalho de parto, denominado período de latência (PL), de 124,8 $\pm 86,4$ horas, contra $30,1 \pm 2,8$ horas daquelas que não apresentaram corioamnionite clínica, números que se mostraram estatisticamente significativos $(p<0,0001)$ quando comparados.
Tabela 1 - Características demográficas, tipo de parto e período de latência das pacientes com rotura prematura das membranas.

\begin{tabular}{ll}
\hline Parâmetros & $\mathbf{n}(\%)$ \\
\hline Pacientes incluídas & $50(100)$ \\
Idade materna (média em anos) & $23,8 \pm 5,6$ \\
Cor & \\
$\quad$ Parda & $24(40)$ \\
Branca & $20(48)$ \\
$\quad$ Negra & $06(12)$ \\
Estado Civil & \\
Casadas & $26(52)$ \\
Solteiras & $24(48)$ \\
Paridade & \\
$\quad$ Nulíparas & $24(48)$ \\
1-2 filhos & $16(32)$ \\
$\geq 3$ filhos & $10(20)$ \\
Tipo de parto & \\
Parto cesáreo & $17(34)$ \\
Parto vaginal & $33(66)$ \\
Abortos prévios & \\
Nenhum & $39(78)$ \\
1-2 & $11(22)$ \\
Idade gestacional na resolução & Corioamnionite clínica presente \\
da gravidez em semanas & $=33,2 \pm 3,9$ \\
(média + dp) & Corioamnionite clínica ausente \\
& $=36,3 \pm 3,8$ \\
Período de latência (horas) & Corioamnionite clínica presente \\
(médias+dp) & $=124,8 \pm 86,4$ \\
& Corioamnionite clínica ausente \\
& $=30,1 \pm 2,8$ \\
\hline &
\end{tabular}

Por sua vez, a média de idade gestacional na resolução da gravidez entre as mulheres com diagnóstico de corioamnionite clínica foi de $33,2 \pm 3,9$ semanas e de $36,3 \pm 3,8$ semanas entre aquelas onde a infecção esteve ausente, diferença que mostrou significância estatística $(p=0,01)$.

Considerando o PL e a presença de corioamnionite clínica (Tabela 2), observou-se que os 15 casos $(30,0 \%)$ que cursaram com corioamnionite clínica apresentaram esse periodo superior a 24 horas. Destaque-se que em 11 mulheres $(22,0 \%)$ entre as 15, esse intervalo foi maior que 72 horas. A análise desses dados mostrou significância estatística $(p=0,0008)$. Saliente-se que no presente estudo não foi encontrado nenhum caso de morbidade febril puerperal entre as cinqüenta pacientes analisadas.

Quanto à presença de corioamnionite histológica, consoante o PL (Tabela 3), verificouse que 20 pacientes $(40 \%)$ apresentaram infecção ascendente (infecção do cório e do âmnio), assim 
distribuídas: entre 12 e 24 horas, 3 casos $(6,0 \%)$, e mais de 24 horas, 17 casos (34\%). Por outro lado, em 19 casos $(38 \%)$ a infecção esteve ausente e em 11 casos $(22 \%)$ as placentas não foram examinadas. A análise desses dados mostrou significância estatística $(p=0,01)$ entre o período de latência prolongado e a presença de corioamnionite histológica.

Tabela 2 - Período de latência e corioamnionite clínica entre as pacientes com rotura prematura das membranas.

\begin{tabular}{|c|c|c|c|c|c|c|c|c|c|c|}
\hline \multicolumn{3}{|c|}{$\begin{array}{l}\text { Corioamnionite } \\
\text { clínica }\end{array}$} & \multicolumn{6}{|c|}{ Período de latência (horas) } & \multirow{2}{*}{\multicolumn{2}{|c|}{ Total }} \\
\hline & \multicolumn{2}{|c|}{$6 \vdash 12$} & \multicolumn{2}{|c|}{$12 \vdash 24$} & \multicolumn{2}{|c|}{$24 \vdash 72$} & \multicolumn{2}{|c|}{$>72$} & & \\
\hline & $\mathrm{n}$ & $\%$ & $\mathrm{n}$ & $\%$ & $\mathrm{n}$ & $\%$ & $\mathrm{n}$ & $\%$ & $\mathrm{n}$ & $\%$ \\
\hline Presente & -- & -- & -- & -- & 4 & 8,0 & 11 & 22,0 & 15 & 30,0 \\
\hline Ausente & 5 & 10,0 & 12 & 24,0 & 13 & 26,0 & 5 & 10,0 & 35 & 70,0 \\
\hline Total & 5 & 10,0 & 12 & 24,0 & 17 & 34,0 & 17 & 34,0 & $50^{*}$ & 100,0 \\
\hline
\end{tabular}

Tabela 3 - Período de latência e corioamnionite histológica entre as pacientes com rotura prematura das membranas.

\begin{tabular}{|c|c|c|c|c|c|c|c|c|c|c|}
\hline \multirow{4}{*}{\multicolumn{2}{|c|}{$\begin{array}{l}\text { Corioamnionit } \\
\text { histológica }\end{array}$}} & \multicolumn{9}{|c|}{ Período de latência (horas) } \\
\hline & & \multirow[b]{2}{*}{$6+12$} & \multirow{2}{*}{\multicolumn{2}{|c|}{$12 \vdash 24$}} & \multirow{2}{*}{\multicolumn{2}{|c|}{$24 \vdash 72$}} & \multirow{2}{*}{\multicolumn{2}{|c|}{$>72$}} & \multirow{2}{*}{\multicolumn{2}{|c|}{ Total }} \\
\hline & & & & & & & & & & \\
\hline & n & $\%$ & $\mathrm{n}$ & $\%$ & $\mathrm{n}$ & $\%$ & $\mathrm{n}$ & $\%$ & $\mathrm{n}$ & $\%$ \\
\hline Presente & -- & -- & 3 & 6,0 & 10 & 20,0 & 7 & 14,0 & 20 & 40,0 \\
\hline Ausente & 5 & 10,0 & 5 & 10,0 & 8 & 16,0 & 1 & 2,0 & 19 & 38,0 \\
\hline $\begin{array}{l}\text { Placenta não } \\
\text { examinada }\end{array}$ & 1 & 2,0 & 3 & 6,0 & 1 & 2,0 & 6 & 12,0 & 11 & 22,0 \\
\hline Total & 6 & 12,0 & 11 & 22,0 & 19 & 38,0 & 14 & 28,0 & 50 & 100,0 \\
\hline
\end{tabular}

Levando em conta o PL e a infecção dos RN (Tabela 4), observou-se que em 16 casos $(31,4 \%)$ os RN apresentaram sinais de infecção neonatal, todos com PL superior a 24 horas, dos quais 12 (23,5\%) tinham esse intervalo acima de 72 horas. Esses números foram estatisticamente significativos $(\mathrm{p}=0,0003)$. A morbidade infecciosa manifestou-se pelos seguintes parâmetros: sinais clínicos de infecção ao nascer, 2 casos (12,5\%); hemograma infeccioso, 5 casos $(31,2 \%)$, e cultura do conduto auditivo e aspirado gástrico, 9 casos $(56,2 \%)$.

Os microrganismos isolados através das culturas de material colhido do conduto auditivo e aspirado gástrico foram: Klebsiella pneumoniae (5 casos), Staphylococcus aureus (2 casos), cocos Gram positivos e Streptococcus agalactiae - grupo B de Lancefield (SGB) (1 caso cada). Não houve crescimento de microrganismos anaeróbios entre as culturas realizadas.
Tabela 4 - Período de latência e infecção do recém-nascido de mulheres com rotura prematura das membranas.

\begin{tabular}{|c|c|c|c|c|c|c|c|c|c|c|}
\hline \multirow[t]{3}{*}{ Recém-nasci } & & & \multicolumn{8}{|c|}{ Período de latência (horas) } \\
\hline & \multicolumn{2}{|c|}{$6 \vdash 12$} & \multicolumn{2}{|c|}{$12 \vdash 24$} & \multicolumn{2}{|c|}{$24 \vdash 72$} & \multicolumn{2}{|c|}{$>72$} & \multicolumn{2}{|c|}{ Total } \\
\hline & $\mathbf{n}$ & $\%$ & $\mathrm{n}$ & $\%$ & $\mathrm{n}$ & $\%$ & $\mathrm{n}$ & $\%$ & $\mathbf{n}$ & $\%$ \\
\hline Infectado & -- & -- & -- & -- & 4 & 7,8 & 12 & 23,5 & 16 & 31,4 \\
\hline Não infectado & 5 & 9,8 & 12 & 23,5 & 12 & 23,5 & 6 & 11,8 & 35 & 68,6 \\
\hline Total & 5 & 9,8 & 12 & 23,5 & 16 & 31,3 & 18 & 35,3 & $51^{*}$ & 100,0 \\
\hline
\end{tabular}

Os resultados perinatais estão distribuídos na Tabela 5; verifica-se que existem diferenças estatisticamente significativas $(\mathrm{p}<0,0001)$ entre os RN infectados quando comparados com os não infectados em relação aos seguintes parâmetros: indice de Apgar no $1^{\circ}$ e $5^{\circ}$ minuto e peso ao nascer. Ocorreram 2 casos $(3,9 \%)$ de óbito fetal e 4 casos $(7,8 \%)$ de óbito neonatal precoce entre os RN infectados, contra nenhum caso de óbito entre os RN não infectados, números que se mostraram estatisticamente significativos quando compara$\operatorname{dos}(\mathrm{p}=0,0004)$.

Tabela 5 - Resultado perinatal dos recém-nascidos hígidos e infectados através da via ascendente nos casos de rotura prematura das membranas.

\begin{tabular}{|c|c|c|c|c|}
\hline \multirow[t]{2}{*}{ Parâmetros } & \multicolumn{2}{|c|}{ Recém-nascido } & & \multirow[t]{2}{*}{ Total } \\
\hline & $\begin{array}{l}\text { Infectado } \\
\text { n ( } \%)\end{array}$ & $\begin{array}{c}\text { Não infectado } \\
\text { n (\%) }\end{array}$ & & \\
\hline $\begin{array}{l}N^{0} \text { de recém-nascido } \\
\text { Índice de Apgar }\end{array}$ & $16(31,4 \%)$ & $35(68,6 \%)$ & 51 & 100,0 \\
\hline $1^{0}$ minuto* & $5,8 \pm 2,4$ & $8,2 \pm 1,0$ & & \\
\hline $5^{\circ}$ minuto* & $7,8 \pm 1,4$ & $9,3 \pm 0,4$ & & \\
\hline Peso (gramas)* & $1911 \pm 667,9$ & $3057 \pm 648$ & & \\
\hline Morte fetal & $2(3,9 \%)$ & $0(0 \%)$ & & \\
\hline Morte neonatal & $4(7,8 \%)$ & $0(0 \%)$ & & \\
\hline
\end{tabular}

* Significância estatística, $p<0,0001$

- Significância estatística, $p=0,0004$

\section{Discussão}

O presente estudo mostrou que o PL prolongado teve associação significativa com a infecção da câmara âmnica. A média do PL entre as mulheres com corioamnionite clínica foi superior à média daquelas sem infecção. O PL de 30,0\% e $22,0 \%$ das mulheres do presente estudo foi superior a 24 e 72 horas, respectivamente, fato em consonância com os achados da literatura ${ }^{10,11}$. A presença de microrganismos patógenos no trato genital das grávidas possibilita sua ascensão à câmara âmnica diante dos casos de rotura das membranas (cório e 
âmnio), podendo assim, acometer as membranas, a cavidade amniótica e o concepto ${ }^{12}$, sobretudo quando for maior o PL. Esse mecanismo seria incontestável se a infecção fosse apenas uma conseqüência da amniorrexe, mas estudos anteriores questionam esse fato e põem a infecção como causa da rotura das membranas ${ }^{4}$. Considerando a infecção como causa da amniorrexe, o PL dessas pacientes tende a ser breve. Entretanto, à luz dos resultados obtidos no presente estudo, parece razoável reforçar a hipótese de que o PL prolongado funciona como fator de risco para o desenvolvimento da corioamnionite clínica.

A presença de $40 \%$ de corioamnionite histológica no presente estudo é semelhante àquela referida por Matheus et al. ${ }^{13}$ em Ribeirão Preto que foi de $38,9 \%$. Vê-se portanto que o percentual de corioamnionite histológica foi superior ao da corioamnionite clínica $(40 \%$ e $30,0 \%$, respectivamente), fato que pode ser explicado pela possibilidade de os microrganismos infectantes ficarem restritos às membranas, não atingindo portanto o líquido amniótico nem o concepto ${ }^{14}$. Por outro lado, estudos baseados em necrópsias mostraram que o comprometimento infeccioso fetal sempre está acompanhado de processo inflamatório dos ane$\operatorname{xos}^{11}$. Saliente-se que, em dois casos de infecção do recém-nascido associada à corioamnionite clínica, o exame histopatológico da placenta não foi realizado, entretanto, se examinados fossem, provavelmente poderiamos diagnosticar comprometimento infeccioso dos anexos, fato que aumentaria a taxa de corioamnionite histológica em mais $4 \%$.

A infecção perinatal decorrente da contaminação da cavidade amniótica no presente estudo ocorreu em $31,4 \%$ dos RN. Em todos os casos de infecção dos RN, o PL foi superior a 24 horas e a média de idade gestacional foi de 33,2 \pm 3 , 9 semanas. Características semelhantes aos achados do presente estudo foram descritas por Mataloun et al. ${ }^{15}$, em que a presença de RN infectado incidiu em $38,1 \%$, todos com PL maior que 24 horas e com idade gestacional $=34$ semanas .

O microrganismo mais freqüente colonizando os RN na nossa casuística foi a Klebsiella pneumoniae (cinco casos), seguido do Staphylococcus aureus (2 casos). O Streptococcus do grupo B de Lancefield (SGB) ocorreu em um caso de cultura positiva do conduto auditivo, resultado semelhante àquele encontrado por nós em estudo anterior no Hospital das Clínicas da Faculdade de Medicina de Ribeirão Preto - USP ${ }^{16}$, no qual o SGB, a exemplo do estudo do HU-UFAL, incidiu em um caso de cultura positiva de material colhido do conduto auditivo do RN. A despeito do pequeno valor de presença do SGB no presente estudo, justificase a necessidade de identificação das pacientes portadoras de RPM que albergam esse microrganismo no trato genital inferior ${ }^{17}$, por ser o SGB a principal bactéria associada à sepse neonatal ${ }^{18}$.

Os RN infectados apresentaram significativamente menores escores de Apgar no $1^{\circ}$ e $5^{\circ}$ minuto, além de peso ao nascer inferior àqueles desprovidos de infecção. Estas alterações podem ser explicadas pelo fato de a infecção ascendente poder provocar edema das vilosidades coriais, comprimir os vasos fetais, e assim propiciar hipóxia perinatal ${ }^{19}$. A mortalidade perinatal foi exclusiva dos RN infectados, incidindo em 11,7\%. Salientese que a prematuridade foi um fator de risco que, associado à infecção, certamente contribuiu para essa considerável taxa de mortalidade perinatal, visto que a média de idade gestacional por ocasião da resolução da gravidez com corioamnionite clínica foi de $33,2 \pm 3,9$ semanas, fato corroborado na literatura (Matheus et al. ${ }^{13}$, Mataloun et al. ${ }^{15}$, Daikoku et al. ${ }^{20}$, Angeles Weintraub et al. ${ }^{21}$ ).

Pela análise dos resultados obtidos no presente estudo, podemos concluir que o periodo de latência prolongado proporciona maior probabilidade de infecção ascendente (corioamnionite), conseqüentemente maior chance de parto prematuro. Portanto, a associação entre infecção ascendente e prematuridade proporciona lesão à mãe, ao feto e ao RN, representada pela infecção materna e perinatal, elevando portanto a taxa de morbidade materna, assim como elevando também a morbidade e mortalidade perinatal. Esses fatos poderão ser minimizados por meio da realização de diagnóstico precoce da RPM, do rastreamento compulsório da infecção materna e do bemestar fetal, associados a uma conduta adequada para cada caso.

\section{ABSTRACT}

Purpose: to evaluate the effects of ascending infection on the mother and newborn in the cases of premature rupture of membranes.

Methods: this was a prospective study, carried out to evaluate 50 pregnant women with premature rupture of membranes (PROM) and their newborns. The clinical chorioamnionitis was investigated by clinical findings (thermal curve, abdominal pain by groping and/or uterine softening, smell and other characteristics of vaginal secretion) and subsidiary tests (white blood cell count and C-reactive protein). The histologic chorioamnionitis was investigated by macroscopic and microscopic study (placenta, membranes and (cord). In the microscopic study optic microscopy with hematoxylin-eosin staining was used. The newborns were evaluated as to weight and Apgar score in the first and fifth minutes of life. White blood cell count, culture of auditory 
canal swab and aspirated gastric material culture complemented the study. Statistical analysis was performed using the Fisher exact test and the Student t-test, with level of significance set at 5\% $(p<0.05)$.

Results: The rate of clinical chorioamnionitis was $29.4 \%$ (15/50), while for histologic chorioamnionitis it was 40\% (20/50). All the cases of clinical chorioamnionitis had latency times (LT) higher than 24 hours. The newborns presented signal of infection in $31.4 \%$ of the cases (16/51), all with LT higher than 24 hours. The main isolated microorganisms of auditive duct and gastric aspirate of newborns were Klebsiella pneumoniae, Staphylococcus aureus, Gram positive coccus and group B Streptococcus. The infected newborns presented lower Apgar scores in the first and fifth minute of life, lower weight and higher perinatal morbidity and mortality when compared with newborns without infection.

Conclusions: based on the analysis of results obtained in the present study, it was possible to conclude that the prolonged latency times increase the possibility of ascending infection, leading to higher possibility of premature delivery and high maternal morbidity (clinical chorioamnionitis), as well as perinatal morbidity and mortality.

KEY WORD: Premature rupture of membranes. Ascending infection. Chorioamnionitis.

\section{Referências}

1. Gibbs RS, Blanco JD. Premature rupture of membranes. Obstet Gynecol 1982; 60:671-9.

2. Evaldson GR, Malmborg AS, Nord CE. Premature rupture of the membranes and ascending infection. Br J Obstet Gynaecol 1982; 89:793-801.

3. Gibbs RS, Sweet RL. Premature rupture of the membranes. In: Creasy RK, Resnick R, editors. Maternal-Fetal Medicine: principles and practice. $2^{\text {nd }}$ ed. Philadelphia: WB Saunders; 1989. p.656720.

4. Johnston MM, Sanchez-Ramos L, Vaughn AJ, Todd MW, Benrubi GI. Antibiotic therapy in preterm premature rupture of membranes: a randomized, prospective, double-blind trial. Am J Obstet Gynecol 1990; 163:743-7.

5. Mercer BM, Miodovnik M, Thurnau GR, et al. Antibiotic therapy for reduction of infant morbidity after preterm premature rupture of the membranes. JAMA 1997; 278:989-95.

6. Romero R, Ghidini A, Mazor M, Behnke E. Microbial invasion of the amniotic cavity in premature rupture of membranes. Clin Obstet Gynecol 1991; 34:769-78.

7. Duarte G. Efeitos da diluição, aquecimento e esterilização do líquido amniótico sobre sua atividade antibacteriana contra o Bacteroides fragilis [tese]. Ribeirão Preto: Universidade de São Paulo. Faculdade de Medicina de Ribeirão Preto; 1988.
8. Gunn GC, Mishell Dr Jr, Morton DG. Premature rupture of the membranes: a review. Am J Obstet Gynecol 1970; 106:469-83.

9. Silva JLP. Rotura prematura de membranas. In: Neme B, editor. Obstetrícia Básica. $2^{a}$ ed. São Paulo: Sarvier; 2000. p.617-26.

10.Bada HS, Alojipan LC, Andrews BF. Premature rupture of membranes and its effect on the newborn. Pediatr Clin North Am 1977; 24:491-500.

11.Garcia AGP. Infecções placentárias. In: Garcia AGP, Azoubel R, editores. A Placenta Humana. $1^{\mathrm{a}}$ ed. Rio de Janeiro: Atheneu; 1986. p.139-52.

12.Bittencourt AL, Garcia AGP. Anatomia patológica das infecções congênitas. In: Monteleone PPR, Valente CA, editores. Infectologia em Ginecologia e Obstetrícia. $1^{\mathrm{a}}$ ed. São Paulo: Atheneu; 1998. p.310-34.

13. Matheus M, Santos MC, Sala MA. Inflamação das membranas: efeitos sobre o nascituro. J Bras Ginecol 1986; 96:275-8.

14.Araújo MCK. Contribuição ao estudo da infecção neonatal em recém-nascidos pré-termo e sua relação com a corioamnionite [tese]. São Paulo: Universidade Federal de São Paulo; 1996.

15. Mataloun MMGB, Prescinotti EAP, Arcas RAM, Ramos JLA, Leone CR. Ruptura prolongada de membranas e infecção neonatal. J Pediatr (Rio de Janeiro) 1997; 73:311-6.

16.Rocha JES, Duarte G, Cunha SP, Nogueira AA, Mauad Filho F. Antibioticoprofilaxia com ampicilina na rotura prematura das membranas. Estudo randomizado e duplo cego. Rev Bras Ginecol Obstet 1999; 21:251-8.

17. Sweet RL, Gibbs RS. Premature rupture of membranes. In: Sweet RL, Gibbs RS, editors. Infectious Diseases of the Female Genital Tract. $1^{\text {st }}$ ed. Baltimore: Williams \& Wilkins; 1995. p.52947.

18. Schuchat A, Oxtoby M, Cochi S, et al. Populationbased risk factors for neonatal group B streptococcal disease: results of a cohort study in metropolitan Atlanta. J Infect Dis 1990; 162:6727.

19.Naeye RL, Maisels MJ, Lorenzo RP, Botti JJ. The clinical significance of placental villous edema. Pediatrics 1983; 71:588-94.

20.Daikoku NH, Kaltreider DF, Johnson TR Jr, Johnson JW, Simmons MA. Premature rupture of membranes and preterm labor: neonatal infection and perinatal mortality risks. Obstet Gynecol 1981; 58:417-25.

21.Angeles Weintraub CD, Menendez Velazquez JF, Valdes Macho JE, Velazquez Espinoza JJ. Ruptura prematura de membrana en embarazos preterminos: análisis de 100 casos. Ginecol Obstet Mex 1988; 56:207-12.

Recebido em: 27/7/2001 Aceito com modificações em: 25/1/2002 